\title{
UM SONHO DE UNIDADE: JOÃO FILGUEIRAS LIMA E SUA GESAMTKUNSTWERK
}

\section{A DREAM OF UNITY: JOÃO FILGUEIRAS LIMA AND HIS GESAMTKUNSWERK}

\section{PAZ, DANIEL J. MELLADO}

Mestre em Arquitetura e Urbanismo, Professor da Faculdade de Arquitetura da UFBA.

Email:danielmelladopaz@hotmail.com.br

\begin{abstract}
RESUMO
Gesamtkunstwerk, a Obra de Arte Total e a Síntese das Artes são conceitos que convergem na História das Artes. Na obra de João Filgueiras Lima, o Lelé, aparece esse sonho de unidade. Em primeiro lugar, no sistema construtivo, com a redução na pré-fabricação a componentes essenciais e versáteis. A evolução da tecnologia eliminou as peças físicas e as tornaram componentes abstratas, sempre aperfeiçoadas. Neles, uma unidade modular, crescentemente universal, regia o conjunto, a ponto de constituir um ambiente integral. Ao mesmo tempo os sistemas técnicos foram se amalgamando cada vez mais. No CTRS - Centro de Tecnologia da Rede Sarah, com a mudança radical da terapia, a própria arquitetura hospitalar e o equipamento médico foram revistos, como meios de transporte e mobiliário, em uma unidade de design e produção. O arquiteto é herdeiro da tradição modernista da síntese das artes. A pré-fabricação foi demandada para transcender o edifício rumo a sistemas globais em gestões totalizantes. O que se relacionava com a procura constante do arquiteto de uma abertura ao futuro de seus edifícios, na forma da extensibilidade e flexibilidade, através da concentração de redes técnicas na estrutura, da ausência de restrições e da provisão de insumos. O labor do arquiteto se desloca para o ciclo de vida do edifício, projetando e operando a própria fábrica que faz os edifícios. Tenta realizar o ciclo completo: projeto, produção das partes, montagem, manutenção, aparelhamento, expansões, mesmo Pesquisa \& Desenvolvimento. Enquanto a unificação do conhecimento na Arquitetura teve como síntese aparente um indivíduo apenas. A racionalidade dos meios e a individualidade não são antitéticos, mas característicos da Era Moderna, e na Arquitetura Moderna, explicando muito do que ocorreu na obra de João Filgueiras Lima.
\end{abstract}

PALAVRAS-CHAVE: obra de arte total, Gesamtkunstwerk, síntese das artes, João Filgueiras Lima, Lelé.

\begin{abstract}
Gesamtkunstwerk, the Total Work of Art and the Synthesis of Arts are concepts that converge in the History of Arts. In the work of João Filgueiras Lima "Lele" that dream of unity also appears. Firstly, in the building system, with its reduction to versatile essential components in the prefabrication. The evolution of technology has eliminated the physical parts and turned it in abstract elements, always improving. In them, a modular unit, more and more universal, ruled the whole, constituting an integral environment. At the same time the technical systems were merging increasingly. In the CTRS - Centro de Tecnologia da Rede Sarah, with the radical change of therapy, even healthcare architecture and medical equipment were redesigned, like vehicles and furniture, in an unity of design and production. The architect is heir to the modernist tradition of the synthesis of arts. Prefabrication has been demanded to transcend the building towards global systems in totalizing managements. It was related to the continuing search of the architect for an openness to the future of its buildings by extensibility and flexibility, through the concentration of technical networks in the structure, the lack of restrictions and the provision of inputs. The work of the architect shifts to the building life cycle, designing and operating the factory that makes the buildings. He tries to perform the complete cycle: design, production of parts, assembly, maintenance, furnishing, expansions, even $R$ \& $D$. Meanwhile the unification of knowledge in architecture had the apparent synthesis in one only subject. The rationality of means and individuality are not antithetical, but characteristic of the Modern Era, and Modern Architecture, explaining much of what occurred in the work of João Filgueiras Lima.
\end{abstract}

KEY-WORDS: total work of art, Gesamtkunstwerk, synthesis of arts, João Filgueiras Lima, Lelé. 
Na obra de João Filgueiras Lima, o Lelé, vemos uma extraordinária unidade em cada resultado, em cada edifício construído. Como podemos compreender essa realização e seus limites, dentro da tradição arquitetônica? Tomaremos a idéia da obra de arte total como ponto de partida.

Richard M. Stein (1973) demonstrou que a proposta da convergência das artes estava presente na tradição romântica germânica, porém foi com Richard Wagner que esta idéia ganhou nome, em seus Escritos de Zurich (Zürcher Schriften), de 1849-51 - em especial Arte e Revolução (Die Kunst un die Revolution) e A Obra de Arte do Futuro (Das Kunstwerk der Zukunft), ambas de 1849 - falando do que deveria ser a obra de arte do futuro: a Gesamtkunstwerk (WAGNER, 1994). Sua tradução literal seria algo como obra de arte total ou obra de arte integral. Wagner falava também de uma obra de arte do futuro "comunitária" (Gemeinsame) (GRAY, 1995). Doravante, usaremos o termo e a tradução consagrada: Obra de Arte Total. O que estava em jogo era a tentativa de recriar o que fora para o compositor o teatro grego clássico: a união de várias formas de Arte em um grande ritual sagrado(1). O drama seria o núcleo para o qual convergiriam de modo subsidiário a poesia, o canto, a música, a pintura e mesmo a arquitetura, na obra de arte do futuro. A idéia wagneriana foi explicitamente adotada por arquitetos ligados ao Art Nouveau como Henry Van de Velde e Victor Horta, embora a idéia de uma renovação total da arquitetura e do seu interior se encontrasse no movimento britânico das Arts \& Crafts e nos seus congêneres continentais. A partir desta vertente, seria em torno da arquitetura que orbitariam os esforços. E, ao longo da história do conceito, identificamos três objetos para a Gesamtkunstwerk, ontologicamente distintos.

O primeiro é o evento, como a ópera, o teatro, performances, e por fim o cinema. O segundo são os espaços construídos: pavilhões temporários, interiores, edifícios, espaços públicos e cidades inteiras. Anders V. Munch (2012) chamará a um de monumento, e ao outro, de momentâneo. Perceberá ainda que existe um terceiro tipo, a partir do trabalho de Peter Behrens para a Allgemeine Elektricitäts-Gesselschaft - AEG, iniciado em 1907, e mencionará os Estados Totalitários (RASMUSSEN e WAMBERG, 2010). Em comum, entidades compostas de pessoas, como o Leviathan de Thomas Hobbes ou os "seres imortais" de Alvin Toffler (1999), como empresas públicas ou privadas, partidos políticos, e Estados.

Quanto aos espaços construídos, a atuação no Brasil orientou-se no sentido restrito da síntese das artes, como um problema de natureza artística, sem os componentes esotéricos ou escatológicos tão comuns na Europa. A síntese das artes não tinha como meta o Novo Mundo, nem a vinda do Homem Novo, sequer as várias formas de Unidade ${ }^{(2)}$. A questão é que o conceito apresenta dilemas estruturais em suas várias formas. Apresentaremos aqueles importantes para o estudo da obra de João Filgueiras Lima.

A Síntese das Artes não implica na Síntese dos Artistas. Wagner ora falava em uma obra de arte comunitária, ora em uma obra total. Indicando uma diferença radical, encarnada nas posturas de Walter Gropius, que deslocara sua atuação ao papel de gestor, e o de Le Corbusier, tão central como autor a ponto de não reconhecer a colaboração de outros e indispor-se contra quem reclamava sua parcela reconhecimento; realizava ele mesmo o projeto, escolhia as cores, pintava os murais, fazia as tapeçarias, as esculturas e relevos, com seu próprio universo simbólico(3).

Outro dilema é o da coesão escalar. A Arquitetura é uma disciplina que tem dentro do seu rol de tarefas lidar com escalas físicas diferentes: o mobiliário, os interiores, os edifícios, os espaços públicos e a cidade. Embora um evento possa ser minuciosamente desenhado em cada detalhe, ainda assim possuirá limites físicos. No caso do Teatro o mais óbvio é o palco, e em casos mais audaciosos, o próprio edifício(4). No espaço construído, não. A procura por obter a Obra de Arte Total tensiona tanto para "baixo" - ao mobiliário e aparato - como para "cima". O limite é o planeta. Lembremos que Corbusier apresentava em 1945, em Les Trois Établissements Humains (LE CORBUSIER, 1979) uma proposta para cidades-lineares por toda a Europa, e Buckminster Fuller (1974) instava que houvesse um planejamento planetário para a "espaçonave Terra", conceito de sua lavra. 
Além do espaço, o tempo é outro dilema intrínseco. O evento pode almejar à perfeita confluência dos talentos por um breve momento; o espaço construído aspira à eternidade. Pretensão que conduzirá ao debate arquitetônico sobre a flexibilidade e extensibilidade, intentos do projetista de controlar a expressão futura do edifício. Mark Wigley, sob a alcunha de projeto total, percebe essa pretensão:

Consideremos "flexibilidade", a ideia de que uma arquitetura pode assumir qualquer arranjo particular. Os projetos mais flexíveis acabam por ter agendas estéticas inflexíveis. Ou, mais precisamente, flexibilidade é uma estética singular em si mesma (WIGLEY, 1998 - tradução nossa).

Precisamos ainda atualizar o conceito de Gesamtkunstwerk na Arquitetura a partir das próprias intenções e atuações da área. São fenômenos correlatos, não explicitamente relacionados com o conceito original, muitos encontrados in nuce na experiência wagneriana. Anotamos como cruciais para a Arquitetura e que devem ser consideradas na Obra de Arte Total: a mecanização do ambiente construído, as novas técnicas construtivas, a reinvenção da Arquitetura, e a reforma do mundo. Estes processos não se mesclam necessariamente, sequer quando é apregoado.

A mecanização do ambiente construído foi estudada por Siegfried Giedion (1969), com o crescente emprego de tecnologias regenerativas (BANHAM, 1984), redes técnicas com suas centrais, distribuidores, conduítes, conectores e aparelhos, mais intensos em certos edifícios, porém profundo no lar. Com entusiasmo ou cautela, os arquitetos foram incorporando estas inovações.

O desenvolvimento tecnológico global, à revelia ou impulsionado pelos arquitetos ${ }^{(\mathbf{5})}$, inexoravelmente resultou em novas técnicas construtivas dos edifícios. Como a produção de peças rígidas de ferro e aço ou a invenção e oferta fácil das chapas de ferro corrugadas (MORNEMENT \& HOLLOWAY, 2007). Ainda que para constituir os mesmos espaços, e seus arranjos e distribuição, e repetir os elementos visíveis (como telhados, pergolados, varandas), já exigem a mudança extrema de todo o detalhamento. $\mathrm{O}$ intento da pré-fabricação compulsoriamente leva a alteração similar. Todos os problemas solucionados ao longo de gerações reaparecem, como a estanqueidade das fenestrações, a rigidez dos cantos, etc.

Com a reinvenção da Arquitetura apontamos que uma das características das vanguardas foi a negação da tradição, e a reinvenção, com níveis e ênfases distintos, de praticamente todos os seus aspectos. Todos os canônicos cinco pontos da Nova Arquitetura de Le Corbusier são inversões radicais de tópicos da Arquitetura tradicional. Nos distintos projetistas, teremos desde mudanças de superfície, como a substituição dos ornamentos pelos artistas Art Nouveau, até aqueles que propunham a modificação da própria maneira de se viver. Esta ambição pode ser entendida como a reforma do mundo, onde Arquitetura, de certa maneira, é a Revolução.

A título de exemplo, temos os conjuntos habitacionais soviéticos, com a redução dos espaços individuais e ampliação dos coletivos para induzir a formação da nova sociedade socialista a partir da reeducação de cada morador, tal como no Edifício Narkomfin (1930), dos arquitetos Moisei Ginzburg e Ignati Milinis, em Moscou. Buckminster Fuller com sua Dymaxion House pretendia modificar completamente o modo de vida do seu usuário, a ponto de revolucionar até a higiene pessoal, por uma nebulização com ar comprimido e água pulverizada (JANDL, 1991)(6). Em uma escala menor, é o ativismo do artista que procura mudar o próprio público, como Wagner desejava transformar a maneira de se fruir uma ópera (WEBER, 1995), com algum êxito, que foi o que the restou do desejo de regenerar a Arte e a própria Sociedade com suas óperas.

Ao fim, são também componentes da obra de arquitetura total também a tecnologia construtiva e suas implicações; as demais tecnologias que comparecem no espaço construído; e todo o alfabeto, sintaxe e vocabulário repropostos pelo arquiteto(7), em uma arquitetura muitas vezes fora de seu tempo, típicas de um futuro que quase nunca se cumpre. Com este arranjo compreendemos João Filgueiras Lima, sob os tópicos a seguir. São desdobramentos parciais da trajetória na pré-fabricação o desenho dos sistemas construtivos, serem estes sistemas sincréticos e a unidade modular que lhes perpassava. O ambiente integral e a conhecida síntese das artes são intentos complementares. A abertura ao futuro, dentro das égides da flexibilidade e extensibilidade, como o papel do arquiteto no ciclo de vida do edifício, também possui uma relação interna. E, por último, o que chamamos da gestão totalizante ${ }^{(\mathbf{8})}$. 


\section{OS CAMINHOS DA UNIDADE}

\section{Os sistemas construtivos}

João Filgueiras Lima abraçou a pré-fabricação em uma sucessão de canteiros e fábricas ao longo de sua carreira. A começar pela experiência da construção de Brasília, trabalhando para o IAPB - Instituto de Assistência e Previdência dos Bancários. Em seguida, na UnB, a cargo da proposta do CEPLAN - Centro de Planejamento da Universidade de Brasília de construir a própria Universidade. Após uma série de obras onde sempre que pôde ensaiou a pré-fabricação, temos o projeto e construção do CAB - Centro Administrativo da Bahia, em 1973, para o Secretário de Ciência, Planejamento e Tecnologia do Estado da Bahia, Mário Kertész, que, tornando-se prefeito em 1979, convida Lelé para montar a fábrica da RENURB - Companhia de Renovação Urbana (1979-82). Teremos, em sequência, a iniciativa da fábrica em Abadiânia (1982-84), a Fábrica de Escolas e Equipamentos Urbanos do Rio de Janeiro (1984-86); a FAEC - Fábrica de Equipamentos Comunitários (1985-89) e a fábrica dos CIACS - Centros Integrados de Ensino (1990), e, por fim, o CTRS Centro de Tecnologia da Rede Sarah, a partir de 1992.

Na mecânica inicial da pré-fabricação a tônica era a redução dos componentes, formando elementos essenciais (pilares, vigas, vedações) e versáteis em duas medidas: reunindo funções distintas no mesmo elemento e podendo ser empregado em situações diferentes. A cobertura construída na RENURB - apenas um pilar e uma laje aparafusados - tanto era um abrigo de ônibus como pôde ser empregada para módulos policiais e abrigo para vendedores de cordel. Justaposto em fileira, formou terminais de ônibus e estações de transbordo em Salvador, como o da Barroquinha, da Rodoviária e Estação da Lapa.

A produção das peças em argamassa armada correspondia em um início a um sistema fechado, a um kit de peças padronizadas. O refinamento da tecnologia da argamassa armada, com o aumento do número de peças, se deu concomitante com a incorporação gradual do emprego do aço (PAZ, 2014), até por fim, ao deslocar a função das estruturas portantes para o aço, constituir um sistema aberto. As peças serão fabricadas, mas não serão mais limitadas.

\section{Os sistemas sincréticos}

João Filgueiras Lima elaborou um sistema que albergava todas as funções e subsistemas em um pequeno número: estruturas, vedações, drenagem, esgoto, eletricidade, acabamento, a iluminação natural, a ventilação. Sendo assim, elas deviam ser sincréticas, com a menor variação possível de peças. Vigas serão ao mesmo tempo calhas, pilares serão tubos de queda. As coberturas, peças versáteis, permitindo ou a exaustão vertical, ou a iluminação estanque, ou mesmo jardins ocasionais. O arquiteto concedera um papel singular à estrutura e aos seus nós, "onde uma multiplicidade de funções se juntam e ganham forma (...) o nível das vigas do teto torna-se um grande condutor de funções múltiplas e a base a partir da qual se desenvolve a cobertura, bem como a divisão espacial do nível inferior" (RISSELADA, 2010, p.107). A malha de serviços se concentra no subsolo e no teto, correndo pelos pilares. Em muitos momentos, é essa armação superior que conduz a infraestrutura, que é uma parte da resposta de Lelé à mecanização da arquitetura.

As instalações elétricas, telefônicas e de sonorização correm em canaletas específicas criadas no próprio desenho das vigas duplas. As luminárias, ventiladores e caixas de som padronizados, produzidos pelo CTRS, são dotados de dispositivos de fixação e de alimentação ajustáveis às abas dessas canaletas. As fiações gerais de lógica correm nas galerias de tubulações (LIMA, 2012, p.128).

Na maturação, a preferência não é mais por uma peça unitária, física, mas por um componente mental, sempre refeito, que não estará petrificado na forma. Nem na fôrma, nos moldes metálicos, caros mas imprescindíveis, da argamassa armada. A viga-calha deixa de ser uma peça em um catálogo de elementos pré-fabricados, e passa a ser um tipo compósito, elaborado com chapas dobradas. Os recursos arquitetônicos e técnicos não são peças materiais, mas tipos na mente do arquiteto e no saber fazer de sua equipe, constantemente testados e aperfeiçoados. 
Tais componentes não são subprodutos inevitáveis da pré-fabricação. Apenas na medida em que precisa reduzir o alfabeto de componentes, necessidade mais urgente quando empregava a argamassa armada. No entanto, ao buscar uma arquitetura extensível, por módulos e unidades adjuntas, o arquiteto precisou elaborar soluções particulares, aplicando tais tipos em independentes técnicas construtivas - alvenaria de tijolos cerâmicos, pré-fabricado de argamassa armada, peças metálicas (PAZ, 2016). Igualmente, ao trazer para dentro do âmbito do projeto os aspectos mecânicos do ambiente construído - a drenagem, os eletrodutos, a instalação hidráulica, os ventiladores - torna seu projeto ainda mais particular.

Não se tratava de um passivo físico, de máquinas e moldes, já que as fábricas eram descontinuadas. E sim de um passivo intelectual, do arquiteto e equipe. A cada nova iniciativa, o que se trasladará é o conhecimento, cada vez mais maduro. Daí serem procedimentos mais abstratos que nos conduzem ao próximo passo dessa espécie de estrutura abstrata, cosa mentale, da obra de João Filgueiras Lima.

\section{A unidade modular}

A pré-fabricação implica em um elemento abstrato: a modulação. Em Lelé, não apenas as peças são moduladas, como tudo aquilo que trabalhará em conjunto precisa encaixar-se nesse grid dimensional, sem necessariamente provir da mesma fábrica. Nas Secretarias do CAB (1973) empregou um módulo de 1,10m, repetindo-o no projeto do Centro de Pesquisas Agropecuárias do Cerrado, Brasília (1978). O módulo foi sendo alterado, na medida em que aprendeu como lidar com ele e a cadeia de fornecedores. No Hospital Sarah de Brasília (1980), adotou o módulo de 1,15m x 1,15m.

As características de funcionamento de um hospital e, no caso, as grandes proporções do edifício, acarretam sempre dificuldades aos serviços de manutenção. No sentido de facilitar esse tipo de rotina administrativa, torna-se essencial um rigoroso estudo de padronização dos elementos de construção (estrutura, vedação, divisórias, equipamentos fixos e móveis, luminárias etc.) (LATORRACA, 2000, p.126).

Nos projetos das escolas transitórias que desenvolveu em Abadiânia nova modificação, de 114,5mm x 114,5mm, devido ao "ajuste de fatores de ordem econômica relacionados com o aproveitamento máximo de materiais industrializados aos de ordem funcional, sobretudo no que diz respeito ao dimensionamento correto dos ambientes internos" (LATORRACA, 2000, p.145). Na implantação do CTRS, novo módulo adotado:

O módulo construtivo de 1,10m × 1.10m, adotado nos projetos dos hospitais de Taguatinga e Sarah Brasília, foi alterado para $0,625 \mathrm{~m} \times 0,625 \mathrm{~m}$. Essa modificação (...) possibilitou melhor aproveitamento dos materiais industrializados, disponíveis no mercado (LIMA, 2012, p.135).

Nessa pesquisa pessoal, Lelé encontrou por fim o que julgava ser o mais eficiente dos módulos possíveis para seus projetos. Mas esse módulo não é empregado por mais ninguém. Qualquer material exógeno requer adaptação. Ou, inviável, precisa ser refeito, nesse mesmo universo particular. Será um problema crucial, que enfrentaremos em tópico a seguir.

\section{O ambiente integral}

Em um edifício de Lelé, em especial nas últimas décadas, tudo perfaz um sistema integrado: estruturas, vedações, acabamento. Isto é típico da pré-fabricação. À medida que o arquiteto desenvolveu sua tecnologia específica de ventilação natural, mais se deu o entrelaçamento do subsolo com o edifício, visto que as galerias visam captar, depurar, resfriar e insuflar o ar para os níveis superiores, além de distribuir a infraestrutura em dutos visitáveis, criando uma plataforma que rege o que está acima. Eis a outra metade de sua resposta à mecanização do meio construído. Os sistemas técnicos - drenagem pluvial, esgotamento, eletricidade, luz natural - se amalgamam, inexoráveis.

Essas galerias exercem tripla função: constituem o próprio sistema de fundações dos edifícios; canalizam o ar externo para todos os ambientes do hospital; e alojam todas as tubulações gerais de suprimento e serviços, possibilitando sua fácil manutenção (LIMA, 2012, p.125).

O salto tecnológico se dá com os hospitais da Rede Sarah, e a constituição do CTRS. Também se trata de uma situação sui generis, pois se tratava de uma forma inteiramente distinta de terapia, exigindo uma revisão 
radical da arquitetura hospitalar ${ }^{(\mathbf{9})}$. O problema que aparecia de entrada era a necessária revisão também dos aparelhos médicos.

A modificação principal nas técnicas de tratamento estabelecidas no anteprojeto desse hospital consistiu na grande mobilidade dos pacientes. Para isso, o conceito convencional de leito foi substituído pelo de "cama-maca", ou seja, houve a troca de um equipamento semifixo por outro de grande mobilidade (LIMA, 2012, p.89).

A cama-maca, pequena obra-prima do design e símbolo do Sarah, é o elemento que permite a mobilidade do paciente e a inversão do procedimento terapêutico, com efeitos na arquitetura: "se não houvesse esse movimento da maca, aquele espaço de exame teria de ser pelo menos 30\% maior. Com isso se consegue condensar as áreas de trabalho do hospital, que é o ideal" (LIMA, 2004, p.74). Os aparelhos médicos são igualmente integrados ao edifício, também redesenhados por sua equipe.

Os equipamentos têm de estar integrados à ideia do espaço. Não se pode conceber um espaço para depois complementá-lo com equipamentos; ao contrário, é preciso conceber um espaço em que os equipamentos façam parte dele (LIMA, 2004, p.74).

Iniciativa que se deu porque, além da carência de equipamentos adequados à nova terapêutica e seu ao espaço arquitetônico, "alguns têm demanda tão pequena que sua produção industrial é inviável" (LIMA, 2012, p.145) ou "eram importados a custos muito elevados de empresas estrangeiras e que, sem o indispensável apoio técnico no Brasil, não ofereciam manutenção confiável" (LIMA, 2012, p.150). Feitos no CTRS, tinham sua manutenção facilitada. O que aponta para uma preocupação do arquiteto quanto ao ciclo de vida do espaço construído por inteiro. Perpassa, observe-se, o sonho de unidade:

Desse imenso arsenal de equipamentos, as características que mais criam problemas para a integração do funcionamento dos setores hospitalares são: a grande variedade dos sistemas de produção empregando as mais diversas tecnologias, a falta de unidade nos desenhos e a ausência de padronização de materiais. Somado a isso, os desenhos criados levam em conta apenas características funcionais e a viabilidade econômica da produção, ignorando as características dos espaços hospitalares em que serão instalados (LIMA, 2012, p.145).

Mesmo aparelhos mais gerais foram redesenhados construídos no CTRS.

O ventilador do meu escritório tem 1,25 m de braço, então chega exatamente no meio da sala. Seu braço é lateral, porque precisávamos fixá-lo não no teto, mas na parede, por onde corre a fiação. A indústria não fornece um ventilador desse, e tivemos que inventá-lo. Temos três ou quatro tipos de ventiladores que fabricamos aqui (LIMA, 2004, p.73).

$\mathrm{O}$ arquiteto argumenta sobre a flexibilidade dos prédios e a seguir, diante do problema dos produtos de mercado, fala sobre a necessidade de inventar um ventilador próprio, pois o mercado não o fornece. 0 aparato precisa adequar-se a esse edifício, de fato não tão flexível. E precisa porque Lelé, ao reinventar a arquitetura, retira da parede a função de suporte geral da infraestrutura. Ao ventilador só resta ancorar-se na estrutura e ajustar-se ao módulo adotado na Rede Sarah. Evidentemente que o mercado não o fornece: não faz sentido que empresas produzam artefatos para cada iniciativa arquitetônica. A partir daí, a Rede Sarah introjeta em seu modus operandi a fabricação de ventiladores para suprir seus edifícios, que se destacam do fluxo da produção material da sociedade.

O CTRS fabricava elevadores e gruas para os pacientes, também não oferecidos pelo mercado.

Outra vertente importante na pesquisa e produção do CTRS se encontra no setor de equipamentos incorporados à construção, tais como os sistemas de transportes verticais específicos e de baixo custo (elevadores, monta-cargas, planos inclinados etc.), que por sua pequena demanda não são produzidos pelas grandes empresas do setor (...) (LIMA, 2012, p.153).

E ônibus para conectar as diversas partes do hospital no terreno, até pela necessária adaptação da camamaca aos veículos. E barcos para o bem-estar dos pacientes.

O CTRS produziu mais recentemente um veículo para o transporte de pacientes nas vias das cidades, com características de conforto semelhantes às dos existentes no Hospital de Salvador. Foi projetado para atender ao transporte de pacientes entre - Hospital de Brasília e o Centro de Reabilitação da Península Norte. Produziu também, em nível experimental, uma barca destinada ao lazer e fisioterapia de pacientes internados no Centro Internacional de Neurociências de Brasília (LIMA, 2012, p.154). 
Uma coisa leva a outra. No entanto, já no RENURB o arquiteto projetara "um veículo leve sobre trilhos que iria resolver todo o problema de transporte da região central (...). Ele chegou a desenhar o veículo, dando a medida, a altura do estribo, sua relação com os pedestres etc." (LATORRACA, 2000, pag.26). Até o mobiliário era fabricado(10).

Do mesmo modo, o potencial de industrialização do CTRS possibilitou redução significativa na terceirização de componentes que quase sempre não se ajustavam corretamente às necessidades requeridas pelo desenho e pela produção, acarretando aumento de custos e perda sensível de qualidade. Assim, as oficinas do CTRS começaram a executar com desenhos próprios todo o mobiliário dos setores de residência médica dos hospitais - sofá, camas, mesas, estantes, armários etc (...) (LIMA, 2012, p.145).

Na história da Arquitetura, o usual é o arquiteto projetar o mobiliário como extensão do edifício. Peter Behrens inaugura a noção da identidade visual e de produto para um ente compósito, concebe os produtos que a AEG irá vender e sua publicidade. Neste caso, o que temos é único: o arquiteto projeta a aparelhagem de um edifício que é, por sua vez, um artefato técnico altamente sofisticado. Mais: de uma série de edifícios, para seu uso próprio. Isso se configurou em meta do CTRS, através do EquipHos, para projetar e produzir "OS equipamentos necessários ao desenvolvimento de novas técnicas de tratamento introduzidas nos hospitais da rede" e "equipamentos hospitalares convencionais sempre que for constatada vantagem econômica ou qualitativa em relação aos oferecidos pelo mercado" (LATORRACA, 2000, p.199). O mobiliário irá como extensão.

\section{A síntese das artes}

No Brasil, o debate sobre a Gesamtkunstwerk pautou-se na chamada Síntese das Artes Maiores - a Arquitetura, a Pintura e a Escultura(11). João Filgueiras Lima é herdeiro dessa tradição, um dos últimos, senão o último, a manter esse bom hábito, que estimula as obras de Artes Maiores, e mesmo Menores ${ }^{(\mathbf{1 2})}$, a povoarem o nosso cotidiano, ao passo em que enriquecem os edifícios. No entanto, há diferenças significativas, e muito podemos compreender se reconstituirmos alguns dos termos e descobertas do debate sobre o tema. Le Corbusier criticava as pinturas convencionais porque desfaziam as paredes, porque "não traz massa de cores suficientemente compactas para qualificar uma parede (...) que ele antes desqualifica a parede, fá-la estalar, explodir, arrebatando sua própria existência" (LE CORBUSIER, 1984, p.64). A cor deveria entrar por panos integrais de cor, na policromia arquitetônica. A observação perceptiva da dissolução do peso da parede era verdadeira. O que era incerto é se constitua o único caminho. Porque a Arquitetura Moderna brasileira aplicou a pintura e o azulejo precisamente para dissolver a parede, retirar-lhe o peso, desfazê-la como fato arquitetônico. Acontece no Edifício do Ministério da Educação e Saúde (1936-47), com os murais de Cândido Portinari e Paulo Rossi Osir a desvanecer o peso da alvenaria, ressaltando o prisma sobre pilotis. Foi com Athos Bulcão que João Filgueiras Lima estabeleceu sua duradoura e bem-sucedida parceria. Dentro dessa atuação conjunta, Lelé compreendia que "a palavra correta é "integração", que deve acontecer não só com a arte, mas também com todas as outras atividades relacionadas com a construção de um edifício" (PORTO, 2005), e não a síntese. Repetia, com provável intenção, a constatação de Lúcio Costa:

Tratar-se-ia, pois, de integração, antes que de síntese. A síntese subentende a idéia de fusão; ora, tal fusão, embora possível e mesmo desejável em circunstâncias muito especiais, não seria o caminho mais seguro e natural para a arquitetura contemporânea (COSTA, 1953).

Ainda Corbusier percebera que a nova Arquitetura sugeria lugares próprios para as artes. Onde Lelé aplica os painéis de Athos Bulcão em seus edifícios? Em partes edificadas no térreo, para fazê-lo passar desapercebido diante do bloco superior tal qual na Residência para Chefe do SNI (1965) e Residência José da Silva Netto (1974), ambas em Brasília. Em grandes paredes em recintos de afluência de público, como na Disbrave (1965) e Hospital Distrital de Taguatinga (1968), em Brasília. Mesmo paredes extensas, como as das escadas rolantes da Estação da Lapa (1979) em Salvador. As grandes empenas de seus edifícios, muitas resultados dos sheds, se tornam superfície ideal para a arte aplicada de Athos; estão sempre nos auditórios, em alguns jardins de ambientação, em vãos das fisioterapias, como no Centro Ambulatorial Infantil de Belém do Pará (2001-2007) e no Centro de Reabilitação Infantil Evandro Carlos de Andrade, Rio de Janeiro (2001-2002). É também saída engenhosa para lotes estreitos, com paredes imprescindíveis, que se transformam em panos de cor, como nas sedes do Tribunal de Contas da União - TCU da Bahia (1995) e de Alagoas (1997). 
A arte de Athos Bulcão se entranhará mais na arquitetura, fundindo a ideia da escultura vazada, com a das peças pré-fabricadas, do papel das vedações leves no interior dos espaços modernistas e dos brises cerâmicos, de concreto e treliças - do modernismo brasileiro. Casava-se ainda com a maneira muito própria do arquiteto fazer entrar a luz natural e os jardins nos espaços construídos, e garantir sua permeabilidade, ou à visão ou à ventilação. Assim, aparece nas portas pivotantes das Creches MAIS - Movimento de Ação Integrada Social (1987) e escolas da FAEC, e acelera vertiginosamente sua interação com o edifício na Rede Sarah, do cercamento exterior às divisórias internas, profundamente necessárias para seccionar as áreas, manter a aeração do lugar e humanizar o ambiente. Chegando aos brinquedos para as alas infantis, em uma inédita interpenetração com arquitetura. Não são mais pinturas ou esculturas, nem o edifício é mais pura arquitetura; eles se interpenetram e complementam, impossível um sem o outro. Agnaldo Farias (2005) observa que por isso não é fácil caracterizar a obra de Athos Bulcão isoladamente: sua atuação não pode ser destacada do edifício e exposta. Tampouco se pode imaginar o Hospital Sarah sem as peças pré-moldadas vazadas que lhe cercam e rompem com a idéia de um aparato utilitário e impessoal. Estamos longe das obras de arte livres, como as de Bruno Giorgi. O arquiteto tinha ciência da maturidade desse resultado:

Lelé - (...) Apesar das propostas de Fernand Léger e de Mondrian de integrar o trabalho dos artistas plásticos na arquitetura, depois do advento da arquitetura moderna, isso só aconteceu com abrangência pelas mãos de Athos Bulcão (PORTO, s/d).

O paisagismo contribuía com esse ambiente unitário. A experiência de Brasília incorporara em definitivo no repertório do Modernismo brasileiro os jardins aquáticos. Longe de ser áulico, o espelho d'água era um procedimento bem-vindo de umectação do ar, absorvido por Lelé, que ainda o empregava para resfriar o ar natural, em sofisticada elaboração bioclimática. Era indispensável para sua arquitetura; nada mais justo que houvesse a sensibilidade em distribuir a vegetação neles, por meio da atuação das paisagistas Alda Rabello Cunha e Beatriz Secco, principais colaboradoras nesse quesito.

Fundamental, como aponta o seu colaborador de longa data, o arquiteto José Fernando Minho(13), era que Lelé não abria mão de seu papel de "coordenador", debatendo a concepção artística, com Athos, e paisagística, com Alda Rabello Cunha e Beatriz Secco, para garantir essa integração, sem nunca meramente terceirizar as colaborações.

\section{A abertura ao futuro}

A carreira de João Filgueiras Lima se dá concomitante com a reflexão internacional da vida útil dos prédios, que os princípios funcionais não mais apontavam para um edifício rigorosamente hipertélico, e sim com certa abertura ao futuro, podendo ser alterado e adaptado, implicando em dois caminhos: a flexibilidade na delimitação dos recintos internos, e a extensibilidade, a expansão física do edifício.

Quanto à flexibilidade, sem dúvida nos hospitais cabia a reflexão da obsolescência tecnológica, do edifício como aparato terapêutico que deveria ser aberto ao progresso.

A natural fragilidade dos programas organizados a partir de uma rotina de funcionamento pré-fixada e com base na utilização de técnicas e equipamentos que a tecnologia modifica a cada dia, torna desejável que o sistema construtivo adotado permita a obtenção de espaços flexíveis e que cada setor possa crescer com independência, sem prejuízo das circulações internas; é de se prever, ainda, para atender a condição do hospital de núcleo de um subsistema, que seu número de leitos possa ser ampliado no futuro, desde que garantidas sua capacidade operacional e a ocupação racional da área urbana que Ihe foi destinada (LATORRACA, 2000, p.126).

Não obstante, Lelé via também essa necessidade em edifícios institucionais, como a Sede do TRE em Salvador (1997), tendo como uma das diretrizes "criar total flexibilidade na ocupação dos espaços internos, sobretudo os destinados a escritórios, visando seu fácil manejamento futuro" (LATORRACA, 2000, p.238). E para escolas, a "flexibilidade (...) ajudará a minorar as deficiências impostas ao método de aprendizado, em virtude de, com frequência, ter-se que superpor faixas etárias e níveis de instrução diferentes misturados num mesmo ambiente" (LATORRACA, 2000, p.142). Mesmo no apartamento para professores (Colina) em Brasília (1963) havia a ideia de "garantir a desejada flexibilização dos espaços internos atendendo às mais variadas composições familiares dos futuros moradores" (VILELA JR., 2011, p.39). Essa flexibilidade não é a do edifício no tempo, mas da sua partição em unidades familiares menores. Pois mesmo em uma residência 
unifamiliar, Lelé considera a flexibilidade como um aspecto importante, como nas de Nivaldo Borges (1975) e Aloysio Campos da Paz (1969), ambas em Brasília.

A flexibilidade se procurava pela concentração de redes técnicas na estrutura e seus nós, reservando às paredes o caráter de vedação. Daí serem feitas de placas portáteis, em tamanho e fixação. Os pisos não são muito mais robustos, apenas o necessário, e não se Ihes confiam muitas funções. Mas a flexibilidade se dá em um sentido duplo. Um deles é a ausência de restrições, com vãos liberados e divisórias móveis. A outra é a provisão de insumos de modo mais redundante possível, a ponto de constituir uma preocupação central nos seus projetos, como nos Galpões de Serviços Gerais da UnB (1962), em que defende que "para se obter flexibilidade no uso do prédio é necessário que as instalações sejam também flexíveis e visitáveis a fim de que se possa mudá-las" (VILELA JR., 2011, p.38). Ou seja, não apenas a existência da rede técnica, mas a possibilidade de manuseio dela em um espaço projetado para tanto. Até porque as instalações se tornariam obsoletas, e precisavam ser atualizadas.

Quanto à extensibilidade, veremos tal preocupação em hospitais; em edifícios institucionais; e mesmo naqueles mais singulares, as residências. Seus primeiros projetos já tentavam alcançar essa qualidade. 0 Hospital de Taguatinga e as Secretarias do CAB foram desse modo concebidos:

Os aspectos abordados acima adquirem maior importância quando sentimos que, devido à natural fragilidade dos programas, esses prédios necessariamente terão que crescer. Além disso, a constante diversificação de setores da administração pública determinará, a curto prazo, o surgimento de novos edifícios que, em alguns casos, por imposições de ordem funcional, terão que manter conexões com os existentes. Assim, além das possibilidades de crescimento linear e de multiplicação dos edifícios proporcionadas pelo tipo de implantação estabelecido, nosso modelo permite a ampliação também por pavimento (LATORRACA, 2000, p.55).

Em ambos os projetos a concepção era a de uma robusta plataforma, capaz de receber andares a mais. No entanto, Lelé vai preferir a justaposição no lugar da sobreposição - daí uma série de recursos arquitetônicos que permitem esse procedimento (PAZ, 2016), garantindo a isotropia de aspectos como drenagem pluvial, entrada de luz, saída de ar. Assim como o arranjo por setores e pavilhões, adjuntos ou separados, em edifícios horizontais com blocos semiautônomos são defendidos por esse princípio. A concepção de hospitais em monobloco mais circulações seletivas "reduziam significativamente a flexibilidade e extensibilidade dos edifícios, condenando, ironicamente, esse modelo tecnológico a muitas dificuldades para absorver os próprios avanços científicos" (LIMA, 2012, p.41). Raciocínio similar foi empregado na residência de Nivaldo Borges, ao dividir o edifício em três corpos justapostos. E ainda quando projetou equipamentos comunitários para prefeituras, como em Abadiânia, e as Casas Comunitárias no Rio de Janeiro (1985-88). Mesmo em um projeto de clube, como o da Associação Portuguesa, em Brasília (1984), pensa na "fácil extensibilidade dos prédios de modo a atender às constantes modificações de funcionamento e diversificação de atividades que sempre caracterizam esse tipo de programa" (LATORRACA, 2000, p.135). Era uma busca constante, e não algo específico de certos programas. O sistema aberto empregado no CTRS permitia um outro grau de uma flexibilidade que buscava desde seu início.

Nada é deixado ao acaso. A abertura para o futuro é uma flexibilidade em termos. Como se dissesse que os próximos textos terão de ser com este idioma, e mesmo com este alfabeto. Na prática acaba sendo mais restritivo que o emprego das formas convencionais de tecnologia construtiva. Pensar em uma maneira coerente de extensão, dentro do mesmo sistema construtivo e lógica compositiva, não implica que os usuários o farão. Os sucessivos improvisos pelos quais as obras de Lelé passaram ao longo das últimas décadas (PAZ, 2006a; 2006b), a partir do raciocínio incremental do pequeno custo e da tecnologia acessível, mostram que as expansões e modificações concebidas pelo arquiteto não eram o mais razoável. Ao contrário, exigem um sofisticado aparato, industrial e projetual. 


\section{O ciclo de vida}

Na trajetória de Lelé, o labor do arquiteto se desloca de projetar edifícios a projetar e operar a fábrica que constrói os edifícios. Realiza o ciclo de vida completo do edifício: projeto, produção das partes na fábrica, montagem, manutenção, aparelhamento, expansões. Entretanto a cadeia funciona apenas se a fábrica estiver instalada, se tudo estiver ajustado. A preocupação com a manutenção se estende também aos equipamentos. João Filgueiras Lima tentou ao máximo instalar sistemas. Na experiência de Abadiânia era parte da definição do problema da escola rural, daí pensar em termos de pequenas usinas, sua localização, distâncias, tempo e condição de deslocamento.

(...) poderíamos afirmar que 5 pequenas usinas de pré-fabricação um pouco mais aparelhadas do que a de Abadiânia, e localizadas em pontos estratégicos do território de Goiás (com raios de ação inferiores a $200 \mathrm{~km}$ ) seriam suficientes para atualizar e manter a rede física de ensino básico do estado (...) (LIMA, 1984, p.25).

O interessante, ademais, é a própria introjeção de algo não claramente exposto na cadeia da construção civil, e que existe somente nas empresas que produzem insumos para a edificação: a Pesquisa e Desenvolvimento. Como na FAEC:

Quando se examina uma cidade, há desde as coisas mais simples, infraestrutura, esgoto, até as mais complexas, que têm de ser revistas. (...) A tendência do conservadorismo, quando está ligado à estrutura capitalista, é de nenhuma empresa fazer uma pesquisa se não der lucro para ela. Fazem pesquisa com remédios, coisas espaciais, mas com a cidade nunca fazem pesquisa porque não dá dinheiro. E a iniciativa privada não vai botar dinheiro para pesquisar depois perder. Se o poder público não fizer pesquisar para depois perder. Se o poder público não fizer pesquisa com a cidade, quem vai? (LIMA, 2004, p.80).

No entanto, dependerá de situações que lhe fogem ao controle. Ou melhor, de oportunidades que se dão a partir da gestão pública, ou de instituições ligadas. Ainda mais se ligada a uma gestão totalizante.

\section{A gestão totalizante}

A pré-fabricação de Lelé vai sendo demandada não para fazer um edifício específico apenas, mas uma série ainda maior. O raciocínio é alçado à necessidade de pensar sistemicamente o projeto das peças. Apresentaremos aqui alguns pontos marcantes dessa trajetória, em ordem histórica, e não de ambição.

Em Salvador, quando da ação de João Filgueiras Lima na Prefeitura, na FAEC, foi a vasta noção antropológica de "cultura" o aglutinador do sistema. No documento "Fundação Gregório de Mattos: roteiro de uma intervenção político-cultural", se lê:

A FGM partiu do princípio de que a cidade é um fato da cultura. O lugar de uma heterogeneidade cultural específica, que a constitui e a imanta. (...) E isto de uma perspectiva antropológica, democrática e popular. Cultura, dizemos, não é simplesmente teatro, ópera, orquestra sinfônica, literatura etc. Cultura é a soma dos atos técnicos e expressivos nos quais se inscreve a criatividade de um povo. Desta perspectiva, todos os nossos trabalhos podem ser definidos como exercícios de antropologia aplicada (RISÉRIO, 2010. p.40).

Ou seja, "quando se trata de um esgoto, da construção de um prédio, também se está fazendo cultura" (LIMA, 2004, p.80), concepção da equipe que estava na FGM: Roberto Pinho, Gilberto Gil e João Santana, então Secretários do Governo Municipal.

Em um grau menor, Lelé entendeu por mobilidade não só a estrutura viária e os meios de transporte, como o acesso pelo menor capilar possível, até a porta da casa do morador. O arquiteto depois reinterpretou tais iniciativas como parte de sua história com a Saúde, ao evitar o próprio acidente ${ }^{\mathbf{( 1 4 )}}$. Já com a Rede Sarah, o que se propunha era uma rede de hospitais pelo país. E o CTRS entrava no projeto, fabricação, construção e manutenção dos edifícios, além do projeto e fabricação do aparato hospitalar. Com isso "os novos hospitais continuaram a ser inteiramente produzidos no CTRS em Salvador e transportados para os locais onde seriam montados" (PINHO, 2010, p.53), a custo inferior ao da construção convencional feita no local.

João Filgueiras Lima tinha para tanto a utensilagem mental, mais do que a material. Podia dar uma resposta, propor uma família de peças, dispostas em procedimentos projetuais e tipos. 
Lelé estava em casa, movendo-se à vontade neste campo sócio-antropológico, no qual a cidade era encarada, simultaneamente, em sua dimensão física e em sua dimensão simbólica e cultural. E ele tinha em suas mãos um instrumento para a execução dos projetos que se impunham, em plano ecológico e social (RISÉRIO, 2010. p.40).

\section{A unificação do conhecimento}

Um problema enfrentado pelo arquiteto ao longo de sua vida foi a especialização do conhecimento, seu aprofundamento em ramos dispersos, pulverizados, por distintos profissionais, e a dificuldade de articulá-los. Foi essa preocupação em comum com Aloysio Campos da Paz que lhes levou a pensar um modo de minorar o problema na Medicina. A inversão do procedimento hospitalar, com o paciente como centro dos cuidados, ancorava-se nesse problema da especialização, já que "no ambulatório o atendimento é em equipe, nunca é isolado. Não tem, como no hospital convencional, um consultório onde o médico fica estático à espera do doente. O médico vem andando até ele" (LIMA, 2004, p.90). Outro efeito da especialização foi o declínio do clínico.

Por outro lado, o grande desenvolvimento da medicina a partir do início do século 20 e a criação das especialidades médicas, que passaram a utilizar diagnósticos e tratamentos sofisticados promovidos por imenso arsenal tecnológico, provocaram também uma natural decadência da ação do clínico ou do antigo médico de família (LIMA, 2012, p.33).

Porém, os efeitos da especialização também se sentiam no rol de arquiteto.

Vemos a fragmentação do saber criando áreas especializadas, e o desafio do arquiteto é integrar esses muitos setores técnicos. (...) É impossível hoje pensar naquela antiga idéia do arquiteto em atividade solitária, um artista que fazia as coisas inspirado numa certa forma. (LATORRACA, 2010, p.10) ${ }^{\text {(15) }}$

O risco era tornar-se refém da tecnologia e esfacelar o conjunto:

A falta de unidade e de equilíbrio que se observa nas soluções arquitetônicas é consequente, sobretudo, da ausência de integração entre os eventos técnicos realizados quase sempre por meio de terceirização descontrolada (LIMA, 2012, p.33).

No caso da especialização do projetista, a perda da sua visão de conjunto, análogo à decadência do clínico, pois, "quando o arquiteto se especializa (...), ele passa a ver o espaço hospitalar como um espaço tecnológico, em que ele tem que saber quais as funções de cada equipamento etc." (LIMA, 2000, p.20). Solucionou-se a dispersão do conhecimento na Medicina via novo arranjo hospitalar, sua gestão e formação de profissionais. Como se daria no caso da Arquitetura?

(...) a atuação competente do arquiteto em projetos de alta complexidade (...) se realiza, sobretudo, com o entendimento abrangente dos fenômenos que interferem na existência humana e com o domínio do arsenal técnico, necessários à prática de suas atividades de profissional generalista. E somente através desse exercício constante poderá desenvolver uma sensibilidade perfeitamente inserida em seu tempo, que the permitirá o diálogo eficiente com todos os profissionais e especialistas que participam do seu processo de criação. E isto significa também que, sem abrir mão de sua postura de artista criador, o arquiteto deve assumir a função primordial de coordenador e de gerador de novas tecnologias, interagindo com uma equipe multidisciplinar presente em todas as fases da produção de sua obra (LIMA, 2012, p.318).

Essa síntese vinha se fazendo em um indivíduo apenas, no próprio Lelé, na medida em que era a figura que transitara de experiência em experiência, o coordenador-geral, a palavra-final, e o homem incansável no projeto, de curiosidade inesgotável para aprender sempre sobre novos detalhes, materiais, máquinas, que impactariam no edifício. A Síntese dos Conhecimentos não implica na dos Conhecedores. Mesmo a arte incorporada ao projeto, antes feita por Athos Bulcão, com a sua morte, não Ihe levou a procurar um outro parceiro possível. Como, segundo o próprio arquiteto, "não encontrei nenhum artista plástico que se identificasse com o meu trabalho como o Athos" (PORTO, s/d), coube-lhe conduzir a tarefa da síntese das artes, daí que em obra no Rio de Janeiro, "em homenagem a ele, eu próprio fiz os trabalhos de integração plástica, sempre usando os ensinamentos aprendidos com o mestre ao longo de todos estes anos" (PORTO, $\mathrm{s} / \mathrm{d})$. 


\section{CONCLUSÃO: O FRACASSO INEVITÁVEL}

A obra de João Filgueiras Lima está calcada na ideia da racionalização da arquitetura. No entanto, a otimização de um meio ainda concede margem de manobra ao projetista. Do contrário, todos os artefatos, até aqueles submetidos a exigências extremas, como os aviões, seriam idênticos. O traço do autor aparece mesmo no homme d'usine. A sutil inclinação conferida pelo arquiteto em prol de soluções a priori, pesos, concessões e limites intransponíveis, garantem que saia de sua mão um produto ótimo, eficiente e, coincidência, similar ao que vinha fazendo antes.

No ideário da Arquitetura Moderna encontramos um pensamento metonímico sobre a industrialização. Entende-se a Fábrica, e análogos, como algo unitário, confundido com sua realidade: um conjugado de várias indústrias, dos mais variados tipos, escalas, orientações, expandindo-se, fechando, separando-se, agregando-se. A Fábrica é um símbolo geral do universo de indústrias, que não possuem uma central de comando, e nem interesse em uma otimização absoluta(16), apenas quando individualmente rentável. Através da metonímia da Indústria, recai-se na indução fácil e falsa de que é algo que pode ser organizado. Ainda mais por alguém fora da cadeia produtiva, como era o arquiteto na maioria das vezes ${ }^{\mathbf{( 1 7 )}}$. Lelé conseguiu algo raro: sua indústria. Ou melhor, conseguiu adquirir expertise e convencer, de quando em quando, gestores públicos a investir recursos estatais para montar fábricas ${ }^{\mathbf{( 1 8 )}}$.

O problema de fundo está na distinção que Friedrich von Hayek (1978) fez entre economia e catalaxia. A economia seria o manejo dos recursos disponíveis para um fim unívoco. Daí a eficiência das "economias de guerra": podem mobilizar os recursos de uma nação para um fim muito bem definido. A catalaxia, sendo um conjunto amplo, difuso e em movimento, de agentes dos mais variados tipos com os mais variados propósitos, não tem uma meta unívoca. Forçá-la a ter é reduzir sua diversidade e mesmo destruí-la, transformando-a em uma economia. Sistemas humanos coletivos sem um projetista são abertos e polissêmicos, com redundância dos meios e a flexibilidade, em consolidação multigeracional e secular. A obra do autor único é mais enxuta e precisa, com sinergia de meios e precisamente por isso menos versáteis diante do imprevisto, do futuro incerto, que é a condição da realidade (JACOBS, 1970; 2001). É a diferença entre os idiomas usuais e aqueles concebidos para serem universais, como o esperanto. Sem poder aprofundar o tema, basta para assinalar que a eficiência de um dado edifício, ou sistema construtivo, só pode ser auferida se houver uma régua unitária e constante, uma meta clara e definida, que só pode ser dada por um indivíduo.

Para Lelé é necessário que o processo de concepção, concretização e execução seja conduzido tanto quanto possível sob o mesmo denominador, para que haja um mínimo de negociações entre as partes envolvidas na construção e maior cooperação entre os diversos participantes. Isto não só aumenta a eficiência [do processo], mas também melhora a qualidade do "produto" (...) (RISSELADA, 2010, p.16).

Muitos dos seus méritos são ao mesmo tempo o seu limite. Tomemos o módulo: vimos quanto tardou para se alcançar uma medida eficiente, e mesmo esta, que vincula todas as partes do edifício a ponto de servir como justificativa para introjetar a produção dos ventiladores, é circunstancial, dependendo da oferta de matéria-prima. O módulo lhe isola em um universo coeso mas díspar dos produtos disponíveis, e incita a aumentar a integridade do ambiente e isolar ainda mais a rede de edifícios.

As diversas tecnologias desenvolvidas no CTRS surgiram da falta de capacidade do mercado em atender as demandas da Rede Sarah. À medida que iam sendo criados padrões e medidas próprias (exemplo: módulos de $62,5 \mathrm{~cm}$ ) foram surgindo dificuldades de compatibilização com os demais produtos de mercado. (TRIGO, 2009, p.40).

O mercado não tem capacidade de atender as demandas do Sarah, nem quaisquer demandas pontuais que não se generalizem e constituam público consumidor. Esse dilema se estendeu às iniciativas fabris do arquiteto: a mudança do conserto para a mera substituição de peças requer economia de escala. Requer um fluxo de saída que justifique a produção, a existência de peças em estoque para reposição e de fornecedores e autorizadas. Caso contrário, a iniciativa fale, como ocorre com frequência. Como Lelé atuava dentro do Poder Público, não era a solvência a questão, e sim a continuidade política.

O extremo grau de sincretismo das peças as torna vulneráveis a quaisquer mudanças, assim como o fato da técnica - construtiva e entranhadas no edifício - quando elevada à expressão figurativa (PAZ, 2006a; 2006b). 
Ademais, Lelé criou um sistema que era uma extensão sua. Aperfeiçoava-se como projetista e pari passu com que refinava sua fábrica, sua equipe, a tecnologia empregada e os recursos arquitetônicos empregados. Porém esse grau ótimo depende do mesmo arquiteto em atuação.

Outro exemplo: as passarelas de pedestres que idealizei para serem colocadas nas grandes avenidas. Pois toda hora surge uma proposta de fazer uma passarela errada. Essas passarelas têm sido utilizadas no Brasil inteiro, não dá para eu ficar de policial a defender a idéia. As de Brasília são horríveis. Eles têm capacidade de produzir em escala industrial e fazem uma coisa daquelas. No Rio também são mal implantadas. Toda vez que vão implantar outra, tento ficar em cima para que façam a implantação correta (LIMA, 2004, p.93).

O sistema construtivo é aberto enquanto leque de possibilidades, não mais preso a moldes, mas não enquanto "código". O que ironicamente compromete a extensibilidade e flexibilidade, motivos de boa parte de suas medidas. A arquitetura de Lelé vai se tornando uma espécie de esperanto arquitetônico, a reconstrução de um idioma próprio, a partir dos anteriores, porém repensado e depurado até seus componentes mínimos. Um idioma novo onde até as letras foram reconstituídas. E que não é inteiramente congruente com a língua vernácula. Nele os pisos e paredes foram "esvaziados" de suas funções e mesmo as janelas, tão comuns, foram revistas; a abertura está sempre acima, ou em protusões para portas. Sequer é uma consequência inexorável da industrialização, e sim o resultado da reinvenção particular da arquitetura, como foi a de Buckminster Fuller (PAWLEY, 1990). Sem capatazes controlando a gestão do objeto, e com uma tecnologia de fácil domínio por terceiros - conhecimento, ferramentas e matéria-prima - a industrialização não é incompatível com o arranjo ad hoc; e este parece ser a condição mesma da sua difusão, vide o caso das kit homes, dos mobile homes (WHITEMAN, 1973; WALLIS, 1991) e dos diners norte-americanos (HURLEY, 2001), e do destino dos abrigos de guerra Nissen e Quonset (DECKER \& CHIEI, 2005).

Não apenas as partes são sincréticas, entrelaçando sistemas, na medida em que um mesmo componente executa muitas funções, ou estes são pensados para se agregarem de maneira ótima. Existe ainda uma unidade dimensional, onde medidas e situações são pensadas correlatas. Não apenas há essa congruência. Há também de material, porque há a unidade de fabricação. As peças saem, na medida do possível, da mesma fábrica - no caso, o CTRS. E, ademais, há uma unidade de design, porque todos vêm do mesmo projetista. Esta não deve ser desprezada, muito menos sua qualidade. O foco em Lelé como construtor costuma diminui seu imenso talento como projetista e como artista. Poucos ou talvez ninguém tenha conseguido o que ele logrou em termos estéticos com a pré-fabricação, ainda mais nas condições do país (PAZ, 2014). Mesmo nos limites mais severos da industrialização, era uma arquitetura pessoal. E quanto mais se desenvolvia como arquiteto, mais explorava os limites dos materiais e da fábrica, e aprendia com as experiências elaboradas, mais pessoal se tornava. Domesticar a fábrica foi lhe dando crescente expressão pessoal.

A reforma do mundo localizada que o arquiteto logrou no período no CTRS se deu pela coincidência desse intento reformista, da arquitetura como extensão de uma nova terapêutica, e pelas condições de estabilidade, recursos, e controle do processo construtivo. Foi a brecha onde pôde atuar para obter a qualidade e eficiência que tanto almejava para a arquitetura. A condição era a fábrica, que ganhou autarquia na entidade, escapando às oscilações dos mandatos dos gestores. Em 2004 já reconhecia a benesse que eram tais condições:

O CTRS é um universo muito pequenino comparado à Faec (...). Mas nós conseguimos muito mais, proporcionalmente. Primeiro, porque estamos aqui há nove anos. Em segundo lugar, temos um controle muito maior das coisas que fazemos, lá havia o problema das pressões políticas. A Faec foi uma experiência muito frustrante (LIMA, 2004, p.80).

Esse ente agregado - a Rede Sarah - permitiu que a unidade fosse alcançada em vários níveis: projeto, construção, detalhes, fabricação, interiores, equipamentos, veículos, paisagismo, obra de arte aplicada. Permitiu que esse tipo de unidade se alcançasse em vários prédios, e que esses prédios fossem unitários entre si, como parte da rede. A ironia é que essa forma específica do sonho de unidade - do ente compósito - é o caso melhor sucedido, mais viável, e ao mesmo tempo, o mais entrópico. É o mais viável, em especial para empresas privadas, na forma da identidade corporativa - um ente que se manifestará como unitário na medida em cada produto seu, cada face sua - porque possui unidade de gestão. Um centro diretor, estável e impositivo. Porém, a mesma continuidade que permitiu o desenvolvimento de tecnologias refinadas foi o fator de sua limitação e extinção. 
Assim, a Fundação das Pioneiras Sociais - criada por Sarah Kubitschek, depois transformada em OS - e o Centro de Reabilitação Sarah Kubitschek, os dois propulsores da expansão dessa tecnologia, que cresceram e se fortaleceram por meio da construção dos hospitais, demonstrando seu potencial e capacidade de atender a demandas de expressão nacional, foram também os responsáveis pela aniquilação do CTRS, ao impedirem que essa tecnologia pudesse ser estendida a outras áreas sociais (PINHO, 2010, p.55)

O fim da parceria de João Filgueiras Lima com Aloysio Campos da Paz, que parece assumir os contornos de um empreendedor público (LEWIS, 1984), foi o suficiente para findar a iniciativa. Igualmente a síntese das artes na obra de João Filgueiras Lima dependia de uma sinergia estabelecida ao longo das décadas, até atingir o seu ápice que são os hospitais da Rede Sarah. Mas a morte de Athos Bulcão a desmontou. Na sua ausência, Lelé lançou de substitutivos extemporâneos e inferiores de maneira análoga ao que ocorrera na obra de Oscar Niemeyer. Integração das artes que o arquiteto elaborou até um grau inédito, e que parece ter sido nele uma sobrevivência de prática bem-vinda que recrudesceu há décadas (ANELLI, 2005; HAAS LUCCAS, 2005). O fato de que, morto Athos, nenhum outro artista havia para ocupar seu espaço demonstra que as novas gerações não compartilhavam dessa esperança.

O sonho de unidade para o espaço construído, em suas diversas variantes e possibilidades, é um esforço tremendo e necessariamente inviável. Cada nova tentativa individual de ordem aumenta a entropia do conjunto ${ }^{(\mathbf{1 9})}$. No empreendimento, emerge o melhor do indivíduo, todas as suas energias e talento submetidos a essa exigência hercúlea. O problema é que a entropia é inevitável, ou melhor, um outro tipo de ordem, complexa, sem um centro diretor ${ }^{\mathbf{( 2 0 )}}$. A Babel é o nosso destino. E a obra de Lelé, seu sonho de unidade, um fracasso inevitável. Esse tipo de ordem é impossível de existir por mais que um breve momento. Mas não deixou de ser um oásis de ordem e beleza. De uma beleza que foi se aprimorando, transcendendo os limites da técnica, cada vez mais a serviço de uma poesia mais lírica, de espaços generosos e amplos, para um homem possivel.

\section{REFERÊNCIAS}

ANELLI, Renato Luiz Sobral. Da integração à autonomia: arte, arquitetura e cultura no Brasil (1950-1980). In: Anais do $6^{\circ}$ Seminário Docomomo Brasil, Niterói, 16 a 19 de novembro de 2005.

BANHAM, Reyner. The Architecture of the Well-Tempered Environment. 2ed. Chicago: The University of Chicago Press, 1984.

BERGHAUS, Günter. The Futurist Conception of Gesamtkunstwerk and Marinetti's Total Theatre. In Italogramma, vol.4, 2012.

COSTA, Lúcio Costa. A Crise da Arte Contemporânea. In: Brasil-Arquitetura Contemporânea, Rio de Janeiro, no1, ago-set 1953, pp. 2-3.

DECKER, Julie; CHIEI, Chris. Quonset Hut: metal living for a modern age. New York: Princeton Architectural Press, 2005.

ELSNER JR., Henry. The Technocrats: Prophets of Automation. Syracuse, New York: Syracuse University Press, 1967.

FARIAS, Agnaldo. A Obra de Athos Bulcão, Ponto Alto da Vertente Construtiva. In: Anais do $6^{0}$ Seminário Docomomo Brasil, Niterói, 16 a 19 de novembro de 2005.

FULLER, Richard Buckminster. Ideas and Integrities. 6ed. New York: Macmillan Publishing Co. Inc., 1974.

FULLER, Richard Buckminster. Operating Manual for Spaceship Earth. New York: Simon \& Schuster, 1969.

GIEDION, Siegfried. Mechanization Takes Command - a contribution to anonymous history. New York: Norton Library, 1969.

GRAY, Thomas S. Um Glossário Wagneriano. In: MILLINGTON, Barry (org.). Wagner: um compêndio. Rio de Janeiro: Jorge Zahar Ed., 1995.

HAAS LUCCAS, Luís Henrique. Da Integração das Artes ao Desenho Integral: interfaces da arquitetura no Brasil moderno. In: Anais do $6^{\circ}$ Seminário Docomomo Brasil, Niterói, 16 a 19 de novembro de 2005.

HAYEK, Friedrich von. New Studies in Philosophy, Politics, Economics and the History of Ideas. London: Routledge \& Kegan Paul, Ltd., 1978.

JACOBS, Jane. A Natureza das Economias. São Paulo: Beca Produções Culturais, 2001. 
JACOBS, Jane. The Economy of Cities. New York: First Vintage Books Edition, 1970.

JANDL, H. Ward. Yesterday's Houses of Tomorrow: innovative American homes 1850 to 1950.Washington D.C.: The Preservation Press/ National Trust for Historic Preservation, 1991

LANGER, Susanne K. Feeling and Form. London: Routledge \& Kegan Paul Limited, 1963.

LATORRACA, Giancarlo. João Filgueiras Lima Lelé. Lisboa/ São Paulo: Editorial Blau/ Instituto Lina Bo e P.M. Bardi, 2000.

LE CORBUSIER. A Arquitetura e as Belas-Artes (1936). In Revista do Patrimônio Histórico e Artístico Nacional, n.19, 1984, p.53-68.

LE CORBUSIER. Os Três Estabelecimentos Humanos. 2ed. São Paulo: Ed. Perspectiva, 1979.

LEWIS, Eugene. Public Entrepreneurship: toward a theory of bureaucratic political power. Bloomington, Indiana, USA: Indiana University Press, 1984.

LIMA, João Filgueiras. Arquitetura: uma experiência na área da saúde. São Paulo: Romano Guerra Editora, 2012.

LIMA, João Filgueiras. Escola Transitória: Modelo Rural. Brasília: MEC/ CEDATE - Centro de Desenvolvimento e Apoio Técnico à Educação, 1984.

LIMA, João Filgueiras. O Que é Ser Arquiteto. Memórias Profissionais de Lelé (João Filgueiras Lima). Em depoimento a Cynara Menezes. Rio de Janeiro: Record, 2004.

LLOYD-JONES, Hugh. Wagner e os gregos. In: MILLINGTON, Barry (org.) Wagner: um compêndio. Rio de Janeiro: Jorge Zahar Ed., 1995.

MARQUES, Andre Felipe Rocha. A Obra do Arquiteto João Filgueiras Lima, Lelé: projeto, técnica e racionalização. Dissertação (Mestrado) Programa de Pós-Graduação em Arquitetura e Urbanismo - Universidade Presbiteriana Mackenzie. São Paulo, set 2012.

MORNEMENT, Adam; HOLLOWAY, Simon. Corrugated Iron - building on the frontier. London: Frances Lincoln Ltd., 2007.

MUNCH, Anders V. Summary. In: From Bayreuth to Bauhaus - The Gesamtkunstwerk and the modern forms of art. Translation by Christian Guldsø. Fra Bayreuth til Bauhaus: Gesamtkunstwerk'etog de modernekunstformer. Aarhus: Aarhus Universitetsforlag, 2012.

PAWLEY, Martin. Buckminster Fuller. New York: Taplinger Publishing Company, 1990.

PAZ, Daniel J. Mellado. Lele'supdate. A apropriação da arquitetura como tecnologia e algumas reflexões sobre o tema - parte 1. In Arquitextos, jul 2006a. Disponível em: <http://www.vitruvius.com.br/revistas/read/arquitextos/07.074/341>

PAZ, Daniel J. Mellado. Lele’supdate. A apropriação da arquitetura como tecnologia e algumas reflexões sobre o tema - parte 2. In Arquitextos, set 2006b. Disponível em: <http://www.vitruvius.com.br/revistas/read/arquitextos/07.076/320>

PAZ, Daniel J. Mellado. O Homem Que Domou a Fábrica: inovação e contexto na obra de João Filgueiras Lima, o Lelé. In: Anais do $5^{\circ}$ Seminário DOCOMOMO N/NE, CD-ROM. Fortaleza: Departamento de Arquitetura e Urbanismo/ UFC, 2014.

PAZ, Daniel J. Mellado. Sol, Espaço e Verde: alguns temas modernistas na obra de João Filgueiras Lima, o Lelé. In: Anais do $11^{\circ}$ Seminário Docomomo Brasil. Recife, 2016. No prelo.

PINHO, Roberto. Lelé: um arquiteto universal. In: RISSELADA, Max e LATORRACA, Giancarlo (org.). A Arquitetura de Lelé: Fábrica e Invenção. São Paulo: Imprensa Oficial do Estado de São Paulo/ Museu da Casa Brasileira, 2010.

PORTO, Cláudia Estrela. Athos Bulcão: A linha tênue entre arte e arquitetura. Brasília: Fundação Athos Bulcão, s/d. Disponível em: <http:// www.fundhathos.org.br

PORTO. Cláudia Estrela. Quando arte e arquitetura se mesclam: a obra de Athos Bulcão e Lelé. In: Anais do 6 Seminário Docomomo Brasil, Niterói, 16 a 19 de novembro de 2005.

RASMUSSEN, Mikkel Bolt; WAMBERG, Jacob (org.). Totalitarian Art and Modernity. Copenhagen: Aarhus University Press, 2010. 
RISÉRIO, Antônio. Um mestre da precisão e da delicadeza estética e social. In: RISSELADA, Max e LATORRACA, Giancarlo (org.). A Arquitetura de Lelé: Fábrica e Invenção. São Paulo: Imprensa Oficial do Estado de São Paulo/ Museu da Casa Brasileira, 2010.

RISSELADA, Max. A pesquisa paciente - o CTRS como laboratório. In: RISSELADA, Max e LATORRACA, Giancarlo (org.). A Arquitetura de Lelé: Fábrica e Invenção. São Paulo: Imprensa Oficial do Estado de São Paulo/ Museu da Casa Brasileira, 2010.

SANTOS, Cecilia Rodrigues dos. A Arquitetura e as Artes Menores. In: VIII Seminário DOCOMOMO Brasil - Cidade Moderna e Contemporânea - Síntese e Paradoxo das Artes, 2009, Rio de Janeiro. Rio de Janeiro: UFRJ, 2009. v. 01.

SCHLEMMER, Oskar; MOHOLY-NAGY, Laszló e MOLNÁR, Farkas. The Theater of the Bauhaus. Middletown, Connecticut: Weslevan University Press, 1971.

STEIN, Jack M. Richard Wagner \& the Synthesis of the Arts. Westport, Conneticut: Greenwood Press, 1973.

TOFFLER, Alvin. A Terceira Onda. Rio de Janeiro/ São Paulo: Ed. Record, 1999.

TRIGO, Cristina Câncio. Pré-Fabricado em Argamassa Armada: material, técnica e desenho de componentes desenvolvidos por Lelé. Dissertação (Mestrado - Tecnologia da Arquitetura). FAUUSP. São Paulo, 2009.

VILELA JR., Adalberto José. A Casa na Obra de João Filgueiras Lima. Dissertação (Mestrado - Teoria, História e Crítica). Programa de PósGraduação da FAU-UnB. Brasília, out 2011.

WAGNER, Richard. The Art-Work of the Future and Other Works. Lincoln \& London: University of Nebrask Press, 1994.

WEBER, William. A Ópera e a Reforma Social. In: MILLINGTON, Barry (org.). Wagner: um compêndio. Rio de Janeiro: Jorge Zahar Ed., 1995.

WIGLEY, Mark. Whatever Happened to Total Design. In: Harvard Design Magazine, Summer 1998, Number 5.

XAVIER, Alberto Xavier (org.). Arquitetura Moderna Brasileira: depoimento de uma geração. São Paulo: Pini/ Associação Brasileira de Ensino de Arquitetura/ Fundação Vilanova Artigas, 1987.

\section{NOTAS}

(1) Ao contrário da maior parte da arte contemporânea, a tragédia grega não era simplesmente um divertimento, mas um ritual religioso; sua temática era a saga, que por sua vera um produto do povo, e que preservava a sabedoria ancestral do povo. A tragédia era uma forma de arte total ou integral (Gesamtkunstwerk), na qual palavras, música e dança desempenham cada qual um papel, sendo tudo feito por uma única pessoa, que não apenas escrevia o texto e a música e coreografava as danças, como também treinava os intérpretes e dirigia a apresentação. (LLOYD-JONES, 1995, p.180).

(2) Aspectos aparentemente factíveis como a unidade entre interior e exterior conviviam com a procura da unidade entre as várias Artes, os vários Artistas, entre o Artista e o Fruidor, entre a Arte e a Tecnologia, mesmo entre o Artista e o Fruidor, a Arte e a Vida e entre as Classes. Ao fundo e ao cabo, uma espécie de harmonia terrestre, com o fim de todas as diferenças.

(3) Este aspecto - do Cosmos idiossincrático - é uma das características de muitos artistas e suas obras de arte totais, que não exploraremos aqui. No caso de Corbusier, foi um mundo simbólico crescentemente denso, visto com mais clareza no seu Le Poème de l'AngleDroit, publicado em 1953.

(4) Como o Festspielhaus projetado por Gottfried Semper para Munich e o efetivamente construído em Bayreuth, para abrigar as óperas de Wagner. O Teatro Total, concebido por Erwin Piscator e projetado por Walter Gropius em 1927 e, no mesmo ano, o Teatro Esférico concebido por Andreas Weininger (SCHLEMMER et al, 1971), e o Teatro Total de F.T. Marinetti, apenas esboçado em linhas gerais (BERGHAUS, 2012).

(5) Não raro com o apelo a ambientes construídos fora do âmbito da arquitetura formal, sem o controle de instituições consolidadas ou o apelo à tradição, com pressões significativas de outra ordem, como estufas, edifícios industriais, vagões de trens, navios (em especial, os transatlânticos), automóveis e aeróstatos como zepelins e aviões.

(6) Fuller pensava na total reorganização da vida humana na terra (FULLER, 1969).

(7) Novamente, podemos encontrar traços desse raciocínio no intento de Richard Wagner, ainda que pontual, ao construir novos instrumentos especialmente para suas óperas. Ou na sucessão das inovações da música erudita, onde compositores como Claude Debussy e Arnold Schönberg chegaram abandonar o sistema tonal, o alfabeto da música ocidental. 
(8) Esta introdução se ressente de apresentar, de forma sumária, conceitos mais complexos, consequência e instrumentos de um estudo maior em elaboração sobre a Obra de Arte Total na Arquitetura. Dilemas e ambições tais como a da Síntese das Artes/ Artistas, da coesão escalar e da reforma do mundo são tanto resultado de uma investigação atual sobre a obra de arquitetos como João Filgueiras Lima (e ainda os mencionados Le Corbusier e Buckminster Fuller), como maneiras de estudar essa mesma obra, rearrumando os dados conhecidos em outra sequência, sob distintos pontos de vista. Assim, aparecem aqui como marco geral e instrumentos de análise da obra de Lelé.

(9) Esta reinvenção se fazia com temas com que trabalhava, alguns vindos da tradição arquitetônica modernista (PAZ, 2016).

(10) Segundo depoimento de auxiliares de Lelé, feito há quase 20 anos, o arquiteto julgara que nenhum móvel disponível se adequava esteticamente aos ambientes criados

(11) Muito pautado pelo debate europeu, em especial o francês, acreditamos, com a atuação de Le Corbusier e André Bloc. As relações entre a Síntese das Artes no debate europeu, brasileiro e a obra de Lelé, são mais ricas e interessantes do que se poderá expor aqui. Serão publicadas em outra oportunidade.

(12) Como mostra Cecília Rodrigues dos Santos (2009), ao apontar, no Brasil, o papel dos azulejos nessa Síntese das Artes na Arquitetura Moderna.

(13) Entrevista concedida ao autor em Salvador (BA), setembro de 2016.

(14) A violência do trânsito, por exemplo, ceifa sistematicamente um enorme número de vidas e cria uma multidão de mutilados e de portadores de lesões irreversíveis que superlotam nossos hospitais, gerando tratamentos complexos na área de reabilitação. Os custos desses tratamentos são comprovadamente superiores aos que se teria com a adoção de medidas simples que garantissem maior segurança aos pedestres e motoristas, como, por exemplo, a organização do trânsito nas cidades - que, embora tardiamente, começa a ocorrer em nosso país -, como a construção de passarelas nos locais em que se registrasse maior número de acidentes. (LIMA, 2012, p.45).

(15) Entrevista a Jotabê Medeiros em O Estado de São Paulo, outubro de 2008.

(16) Não é acidental que a primeira iniciativa de algo do gênero ao nível nacional, com a economia de guerra de Walter Rathenau, prestou-se, como técnica administrativa, ao estado totalitário nacional-socialista posterior que, sem a posse dos meios de produção, tinha o controle efetivo. Ser uma economia, e ser de guerra, será algo importante.

(17) Outro apelo à Política. A defesa mais ardorosa da racionalização da produção talvez tenha sido o do Movimento Tecnocrático norteamericano, onde muitos engenheiros de formação reclamavam para si a capacidade técnica e intelectual de saber como usar melhor os recursos... de outrem (ELSNER JR., 1967).

(18) Daí o erro de André Felipe Rocha Marques de achar que o "controle quase total por parte do arquiteto, trazendo para si toda a responsabilidade pela obra, desde o traço, até a usinagem e montagem final" seja uma "contradição entre o engajamento ideológico do arquiteto e seu controle total sobre a obra" (MARQUES, 2012, p.48). É constitutivo, como uma das possibilidades presentes no nascedouro e realizadas em trajetórias individuais, da Arquitetura Moderna, e mesmo da Era Moderna.

(19) A frase feliz devo ao amigo Eduardo Pierrotti Rossetti, embora não sobre esse tema específico.

(20) No século XX, o sonho tecnocrático da racionalidade dos meios e fins, da eliminação dos desperdícios, com o justo e preciso encaixe de cada coisa, a adaptação com o meio - físico, cultural - e das partes internas, é uma constante, que não cabe aqui explorar.

NOTA DO EDITOR (*) O conteúdo do artigo e as imagens nele publicadas são de responsabilidade do(s) autor(es). 